\title{
Tribological Analysis on Basalt/Aramid Hybrid Fiber Reinforced Polyimide Composites: An Alternate Brake Pad Material
}

\author{
A.A. Jeya Kumara,*, N.P. Akshy Ramaseshanª, T. Lakshmanan ${ }^{a}$ \\ aDepartment of Mechanical Engineering, SRM Institute of Science and Technology, Kattankulathur, Kanchipuram \\ 603203, Tamil Nadu, India.
}

Keywords:

Polyimide

Basalt fiber

Aramid fiber

Pin-on-disc

Wear rate

Coefficient of friction

* Corresponding author:

A.A. Jeya Kumar

E-mail:aruljeyakumar@yahoo.co.in

Received: 22 June 2020

Revised: 28 April 2020

Accepted: 2 December 2020

\begin{abstract}
A B S T R A C T
Fiber reinforcement in polymer matrix contribute significant role in improving mechanical and tribological behavior of any composite for friction application. Hence such composites are developed by selecting suitable matrix and reinforcement materials. In the present study three frictional composite materials were prepared by varying basalt fiber, aramid fiber and hybrid of both theses fibers. Namely Basalt Fiber reinforced composite (BFRC), Aramid Fiber reinforced composite (AFRC) and Hybrid of these fibers reinforced Composite (HFRC), with polyimide matrix. The other ingredients were mixed in constant proportions to enhance the frictional property of the composites and specimens were prepared using hot compression molding machine. The pin-on-disc testing was carried out with different loading condition of 20, 30 and $40 \mathrm{~N}$ and varying sliding velocities of 150,200 and $250 \mathrm{rpm}$ to understand the effect of these parameters on coefficient of friction and the wear rate of specimens. Based on results, contour were developed using Minitab software. HFRC shows the best tribological characteristics compared to BFRC and AFRC. The contact temperature is less for HFRC due to the good heat conduction by hybrid fibers. The thermal stability and the degradation of composites were study from Differential scanning calorimetry (DSC) and Thermogravimetric Analysis (TGA) respectively. It is observed that HFRC has better thermal stability. The Scanning Electron Microscopy images shows better bonding of matrix and fiber for HFRC compared to other composites and various mechanisms were identified along the wear regime areas.
\end{abstract}

(C) 2021 Published by Faculty of Engineering

\section{INTRODUCTION}

Brakes are essential parts of any system that is in motion, which is responsible for the safety of the machine as well as the human beings, by gradually slowing down and stopping the moving parts. It is an abrasive device that converts the kinetic energy of the rotating 
system in to heat energy that is lead into the atmosphere. Various kinds of brake pad materials mostly employed in automotive are semi-metallic brake pads, non-asbestos organic (NAO) and low-metallic, NAO and ceramic based brake pads [1]. The quality of disc brake materials is highly dependents upon the mechanical and thermal behaviour of the materials used [2].

Due to the health issues caused by asbestos, fiber reinforced NAO composites are mostly used in brake materials in automotives. Polymer composites have been gaining a lot of attention in recent years owing to their ease in processing at the same time offering excellent wear resistance $[3,4]$. Several hundred ingredients have been amalgamated with the brake pad composites to attain the needed quality $[6,7]$. These Ingredients are classified as binders, friction generators, and fibers $[8,9]$.

The binders are used to provide the structural reinforcement and effective adhesion to hold rest of the ingredients together. Polyimide (PI) has gained lot of attraction as a recent binder, due to their following proprieties such as excellent mechanical properties, low wear rate, high thermal with stand ability, high constancy in vacuum, low radiation and non-soluble [1012]. Excellent sliding property can be achieved by combination of proper fiber and solid lubricant [13].

Fibers are mainly used for reinforcement and to enhance the thermal stability of the composites. Basalt fiber is popularly known for its anti-corrosion ability, fire resistant by nature and good resistance to abrasion. Its strength is also higher than both fiberglass and carbon fiber [14]. Researchers have demonstrated and proved that incision of such fibers as reinforcement has enhanced the wear resistance, increase the coefficient of friction as well as thermal stability [5]. Basalt fiber reinforced Polyimide composites displayed an improved wear resistance compared to Poly vinyl product [10]. Aramid fiber is one of the commonly used fibers as reinforcement that decreases the wear rate, due to its physical properties like fibrillation, elongation, ductility and thermal stability $[12,14]$. The hybrid reinforcement of basalt sand aramid fiber in binder material enhances the strength, thermal stability and wear resistance of the composite [15-18].

Abrasives materials are widely used to reduce the wear rate and enhance frictional coefficient. Filler are generally used to fill up the space and to give stability at elevated temperatures, materials used as fillers may be either organic such as sawdust, coconut, walnut and cashew nut shell powder $[19,20]$ etc., or inorganic such as barium sulphate, calcium carbonate, vermiculate etc. that decreases wear. The other filler materials such as iron powder, copper powder and aluminium are used to increase friction in the composites. Lubricant reduces direct contact of the interacting frictional surfaces by preventing micro sticks to the rotor effectively decreasing the wear rate, graphite, molybdenum disulphide are some widely used lubricants $[21,22]$.

Various research studies carried out have identified that during the breaking operation the major possible failures are chemical modification, thermal instability, high wear rate and propagation of Cracks [23]. Other investigations conducted have also revealed the different means by which wear can take place in polymer composites are by fiber damage, fiberbinder agglomeration, and matrix crack [24-26]. Some additional but vital means of wear are pull-out of fiber, matrix wear caused by fibre movement, matrix peel-off, twist of the fibers due to shear, and wear track edge bend [27-29].

When a brake is applied the temperature at the contact area of a frictional material increases, which causes failure of brake pad [30]. A frictional material should be thermally stable, when the contact temperature increases beyond 600 oC normally [31]. At any temperature below 800 oC the brake pad material should not have any chemical changes and eventually should not decompose. In many existing frictional materials the chemical structure changes [32].

Therefore, in the present work new frictional composite materials was developed by blending and compacting polyimide matrix with basalt and aramid fibers as reinforcement along with appropriate fillers to enhance the frictional properties. Wear resistance and coefficient of friction was checked by performing pin-on- disc test and the tribological characteristic of the friction composite was examined. 


\section{MATERIALS AND METHODS}

\subsection{Materials and ingredients}

The basic raw materials selected for the development of the frictional material are thermoset polymer binder and high strength fibers. Polyimide powder used as the binder (PI) in this work was obtained from ABR ORGANICS LIMITED (Andhra Pradesh, INDIA). The polyimide powder and physical properties are shown in Fig. 1a and Table 1a respectively.

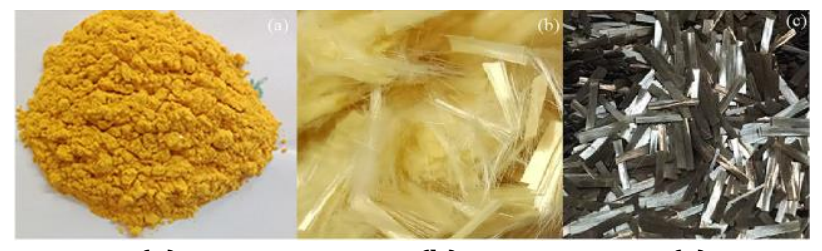

(a)

(b)

(c)

Fig. 1. (a) Polyimide Powder, (b) Aramid Fiber, (c) Basalt Fiber.

Table 1a. Physical properties of polyimide.

\begin{tabular}{|l|c|}
\hline Chemical & \% \\
\hline Silicon dioxide & 52.8 \\
\hline Aluminium oxide & 17.5 \\
\hline Iron (III) oxide & 10.3 \\
\hline Magnesium oxide & 4.63 \\
\hline Calcium oxide & 8.59 \\
\hline Sodium oxide & 3.34 \\
\hline Potassium oxide & 1.46 \\
\hline Titanium dioxide & 4.38 \\
\hline Phosphorus pentoxide & 0.28 \\
\hline Manganese oxide & 0.16 \\
\hline Chromium(III) oxide & 0.06 \\
\hline
\end{tabular}

Table 1b. Chemical composition of Basalt fiber [33].

\begin{tabular}{|l|c|}
\hline Appearance & Pale Yellow \\
\hline Bulk Density & $0.8 \mathrm{gm} / \mathrm{cc}$ \\
\hline Melting Temperature & $110 \mathrm{oC}$ \\
\hline Viscosity & $0.06 \mathrm{dl} / \mathrm{gm}$ \\
\hline Solubility & $\mathrm{MF}$ Solution \\
\hline Curing Temperature & $180-220 \mathrm{oC}$ \\
\hline
\end{tabular}

Aramid fiber was obtained from Go Green Products, Chennai, India. Aramid has a tensile strength of $2700 \mathrm{MPa}$ and Young's modulus of $70.5 \mathrm{GPa}$. The Figure 1b shows the schematic sketch of aramid fiber. Saline treated chopped basalt fiber was purchased from muthagiri Industries PVT LTD, Mumbai, India. Basalt fiber has tensile strength of $3500 \mathrm{MPa}$, elastic modulus of $95 \mathrm{GPa}$ and elongation at break of
$2.4 \%$. The Figure $1 \mathrm{c}$ and Table $1 \mathrm{~b}$ represents the sketch and chemical composition of basalt fiber respectively. The other filler ingredients as indicated in Table 2 were procured from Lab chemicals, Chennai, India.

Table 2. Ingredients for the compaction of three different brake pad composites.

\begin{tabular}{|l|c|c|c|}
\hline Ingredients & $\begin{array}{c}\text { Weight } \\
\text { fraction for } \\
\text { basalt fiber } \\
\text { reinforced } \\
\text { composite } \\
\text { (BFRC) }\end{array}$ & $\begin{array}{c}\text { Weight } \\
\text { fraction for } \\
\text { Aramid fiber } \\
\text { reinforced } \\
\text { composite } \\
\text { (AFRC) }\end{array}$ & $\begin{array}{c}\text { Weight } \\
\text { fraction for } \\
\text { Hybrid fiber } \\
\text { reinforced } \\
\text { composite } \\
\text { (HFRC) }\end{array}$ \\
\hline Polyimide & 31 & 31 & 31 \\
\hline Aramid & 6 & - & 3 \\
\hline Basalt & - & 6 & 3 \\
\hline Barite & 10 & 10 & 10 \\
\hline $\begin{array}{l}\text { Potassium } \\
\text { titanate }\end{array}$ & 6 & 6 & 6 \\
\hline Vermiculate & 7.5 & 7.5 & 7.5 \\
\hline $\begin{array}{l}\text { Molybdenum } \\
\text { disulfide }\end{array}$ & 1.3 & 1.3 & 1.3 \\
\hline $\begin{array}{l}\text { Aluminum } \\
\text { oxide }\end{array}$ & 7 & 7 & 7 \\
\hline Graphite & 11.2 & 11.2 & 11.2 \\
\hline Coke & 15 & 15 & 15 \\
\hline $\begin{array}{l}\text { Magnesium } \\
\text { oxide }\end{array}$ & 5 & 5 & 5 \\
\hline
\end{tabular}

\subsection{Treatment of aramid fiber}

Aramid fiber was soaked in $10 \%$ sodium hydroxide for 1 hour and then washed with distilled water 4 to 5 times so that the PH value reaches 7 . The fiber was dried in hot air oven for $5 \mathrm{hrs}$, maintaining $80 \mathrm{oC}$ to remove the moisture. Polyimide (PI) powder is dissolved in DMF (Dimethyl foramide) solution by adding pinch by pinch until all the powder clearly dissolve in DMF and the color of the solution turns pale yellow. The dried aramid fiber is soaked in this DMF/PI mixed solution and left in it for 30 minutes. Finally the fiber was dried for 5 hrs at $80 \mathrm{oC}$ in oven [23].

The surface treatment is basically to carry out in order to have better adhesive bonding and improve interfacial bonding between the matrix and other ingredients and with the fibers [34]. The saline treatment in basalt fiber will increase the roughness and shear strength. The surface treatment of aramid fiber by coating PI matrix with coupling agent DMF will increase the surface roughness and interfacial shear stress 
[35]. Hence the treatment of fibers will increase the bonding nature of the composites.

\subsection{Preparation of the composite}

Frictional composites of three varying composition were made using polyimide powder reinforced with basalt, aramid and there hybrid. Table 2 shows the other ingredients namely abrasives, fillers, friction modifiers and solid lubricants used for the preparation of the composite. The constituents were thoroughly mixed using a low speed stirrer for around $1 \mathrm{~min}$ to get a homogeneous mixer. The die, with 12 cylindrical cavity of dimension (dia. $=10 \mathrm{~mm}$ and length $=30 \mathrm{~mm}$ ) was pre heated to $180 \mathrm{oC}$ inside compression molding machine. The die was removed and mixed powder was then poured into it, rammed and closed. The mold was put back into the compression molding machine again, gradually applying the load till the mixture is completely compressed and the temperature of $180 \mathrm{oC}$ for a period of 1 hour was maintained. The maximum load applied is 20 $\mathrm{MPa}$ for about 1 hour. The mold was removed and settles to cool down to atmospheric temperature then the specimens were removed from the die. Figure 2 represents the specimens obtained by hot compression molding.

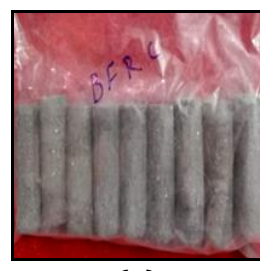

(a)

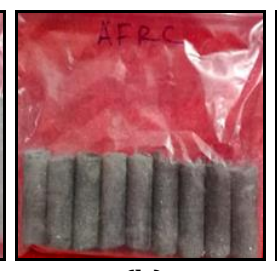

(b)

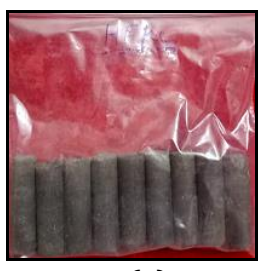

(c)
Fig. 2. (a) BFRC specimen, (b) AFRC specimen, (c) HFRC specimen.

\subsection{Post curing of specimens}

Post curing of the composite (in air) at $200 \mathrm{oC}$ for 5 hours; This done by gradually increasing the temperature, like $50 \mathrm{oC}$ and maintain it for 1 hour, then increase the temperature to $100 \mathrm{oC}$ and maintain it for one more hour. Further the temperature is raised to $150 \mathrm{oC}$ and allows it under the same condition for 30 minutes and after that the temperature is increased to $200 \mathrm{oC}$ and maintained for 2 hours continuously. Finally the oven is switched off and allowed to cool gradually without taking the specimen out of the oven for 10 hours. This is done to reduce the heat of the composites gradually.

\subsection{SEM analysis}

Scanning Electron Microscope (SEM) image of the three frictional composite was taken for the purpose of examining the morphological structure of the composites and to understand the positions of the ingredients and fibers in the binders. The FE-SEM images were observed in FEI Quanta 200F instrument available at NCR, SRMIST, Chennai, India.

\subsection{Rockwell hardness test}

Hardness of the composites was tested in Rockwell Hardness testing machine at $100 \mathrm{kgf}$ and $12.70 \mathrm{~mm}$ ball indentor S Scale (SRMIST, KTR). The hardness values of the composites were checked to identify the disc material to be used in pin-on-disc apparatus. It is clear that the hardness of the disc should be maximum, when compared to material that slights on it to understand the wear properties of the materials.

\subsection{Wear test}

Frictional and wear behavior for dry sliding condition of the composites were made according to ASTM G99 test standard and examined using Pin-on-disc tester. The test were conducted at Normal Load and sliding velocity of 20, 30 and 40 $\mathrm{N}$; and 150, 200, $250 \mathrm{rpm}$ for a period of $20 \mathrm{~min}$ respectively. The test reveals the values of coefficient of friction and wear loss along with loss of weight of the specimens. Around five specimens in each trial were tested and average value was recorded with standard deviation. The Figure 3 shows the pin-on-disc setup used in this testing process.

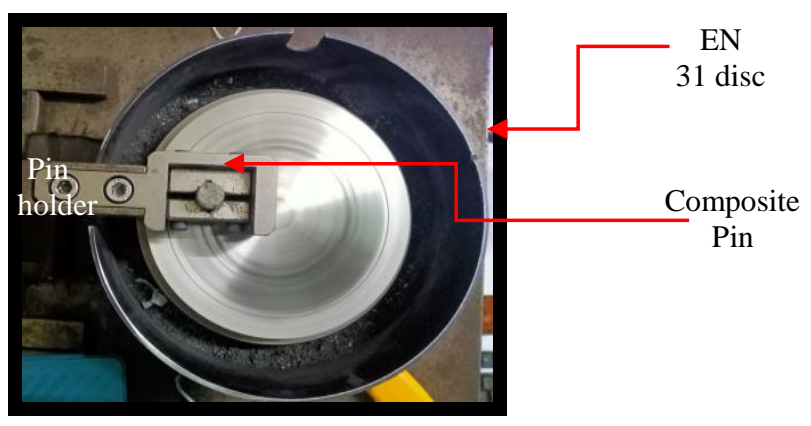

Fig. 3. Pin on disc tester.

Generally the weight loss of the specimen occurs in the form of material removal subjected to friction contact, weight before and after the test is measured used gram weighing machine. The 
contact temperature was measured using a thermocouple inserted in the holes provided in the specimens. The Wear Loss is the thickness of pin layer removed after friction in the pin-ondisc tester.

$$
\text { Wear Loss }(\mu \mathrm{m})=\mathrm{Lb}-\mathrm{La}
$$

Where, Lb - Length of pin before friction action La - Length of pin after friction action.

\subsection{Thermal test}

The samples are tested for analyzing the thermal behaviour in DSC 200F3 Maia Machine at Netzsch laboratories, Chennai. The temperature of observation is from 30 to 500 oC by heating at the rate of $10 \mathrm{~K} / \mathrm{min}$ under nitrogen atmosphere. The degradation properties of the samples are tested by TGA, carried out at CIPET, Chennai. Samples are tested at temperature between 50 and $900 \mathrm{oC}$ at the heating rate of $20 \mathrm{oC} / \mathrm{min}$.

\section{RESULTS AND DISCUSSION}

\subsection{Selection of disc material based on hardness}

Table 3 shows the hardness of the composites used for study. BFRC composite shows higher hardness of 50 when compared to AFRC and HFRC. As the hardness of the material composites is in between 40-55 HRS, EN31 disc material is chosen for the wear test.

Table 3. Hardness of the Sample in HRS.

\begin{tabular}{|l|c|c|c|c|c|}
\hline Samples & Trial & Trial & Trial & Trial & Average \\
\hline BFRC & 50.5 & 55 & 56.6 & 58.5 & $55 \pm 0.20$ \\
\hline AFRC & 38.8 & 40.5 & 42.7 & 41.9 & $41 \pm 0.10$ \\
\hline HFRC & 48.5 & 51.8 & 52.6 & 53.5 & $51 \pm 0.40$ \\
\hline
\end{tabular}

\subsection{Tribological characterization of BFRC}

Figure 4a shows the SEM image of BFRC, that shows the basalt fiber are randomly oriented, deeply rooted and has fused well with the PI matrix and other ingredients. This in turn increases the tenacity as well as improves the hardness of the composite [36]. From Figs. 4b and $4 \mathrm{c}$ it is clear that frictional coefficient decrease as the load increases and it increases as the sliding velocity increases under specific loading condition.

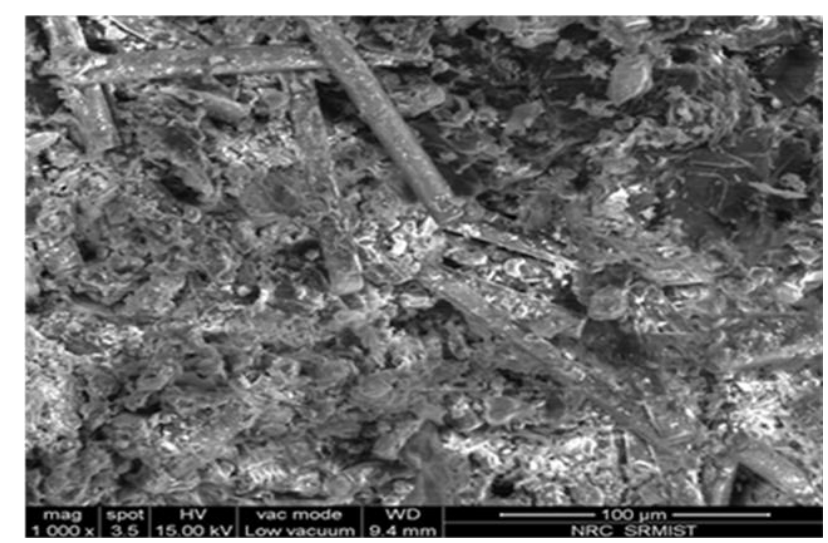

(a)

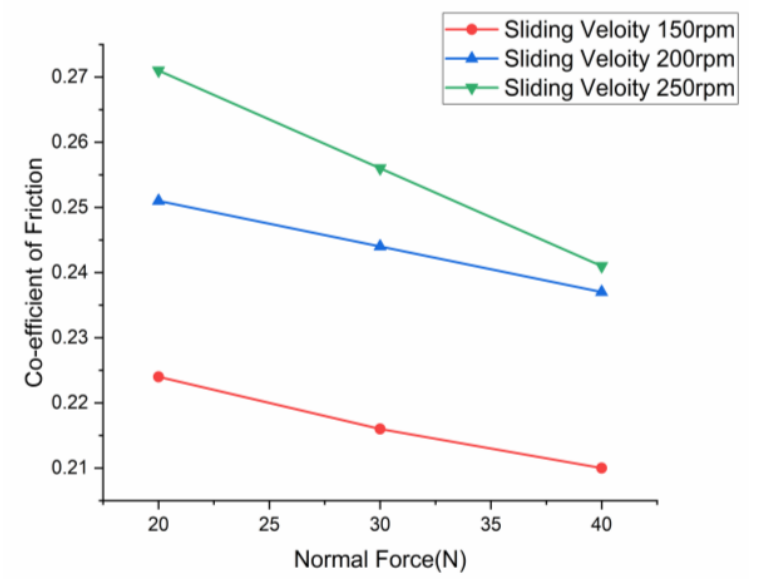

(b)

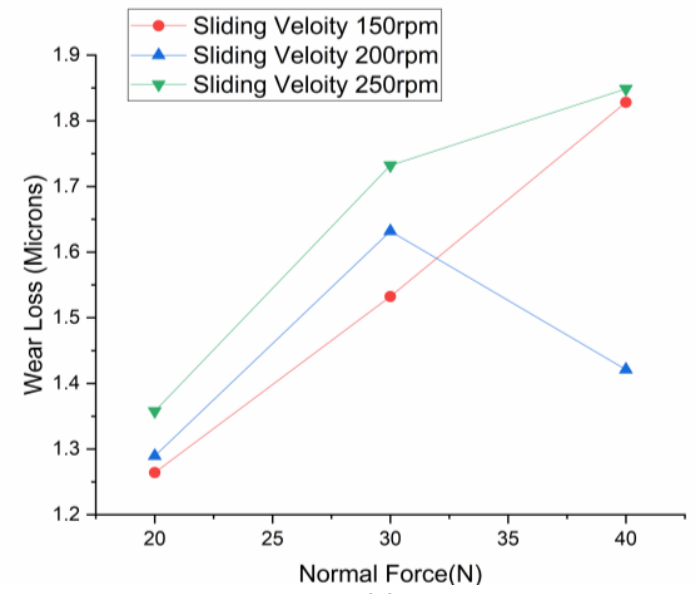

(c)

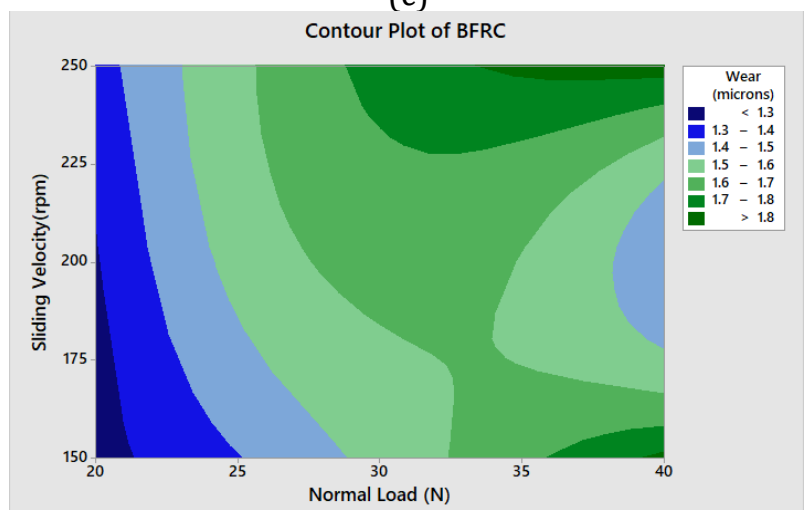

(d)

Fig. 4. (a) SEM Image of BFRC, (b) Coeff. of friction of BFRC, (c) wear loss of BFRC and (d) Contour plot of BFRC. 
Table 4. Wear Loss and COF of BFRC specimens.

\begin{tabular}{|c|c|c|c|c|}
\hline Normal Load (N) & Sliding Velocity (rpm) & Wear Loss (microns) & Frictional coefficient $(\boldsymbol{\mu})$ & Contact Temperature ( ${ }^{\mathbf{C}}$ ) \\
\hline 20 & 150 & 1.2641 & 0.224 & 112 \\
\hline 30 & 150 & 1.5324 & 0.216 & 114 \\
\hline 40 & 150 & 1.8280 & 0.210 & 115 \\
\hline 20 & 200 & 1.2896 & 0.251 & 119 \\
\hline 30 & 200 & 1.6318 & 0.244 & 121 \\
\hline 40 & 200 & 1.4210 & 0.237 & 122 \\
\hline 20 & 250 & 1.3577 & 0.271 & 125 \\
\hline 30 & 250 & 1.7321 & 0.256 & 126 \\
\hline 40 & 250 & 1.8487 & 0.241 & \\
\hline
\end{tabular}

This may be due to development of friction layer, which is harder at lower load and as load increases the asperities at the interfaces gets deformed and breaks, results in the formation of loose granular layer and increases the contact area, this leads to the increase of frictional coefficient [37]. Table 4 represents the wear test results obtained for BFRC. The wear rate is found to increase at low and high velocity, this may occur due to the raise in temperature. This results in strength reduction due to fiber-matrix bonding weakness that leads to continuous wear loss [38,39]. It can be observed that at higher speed and with increase in load there is a small decline in wear may be because of greater adhesion particles with the pad surface. When load is increased further the tackiness wears-off increasing the wear rate [40].

Figure $4 \mathrm{~d}$ represents the contour plot of the wear loss of BFRC specimen under normal load and specific sliding velocity. It can be inferred that $60 \%$ of the contour area represents mild wear loss (1.0 to $1.5 \mu \mathrm{m}), 30$ $\%$ area represents sever wear loss (1.5 to 1.75 $\mu \mathrm{m})$ and finally ultra-sever wear loss is $10 \%$ (more than $1.75 \mu \mathrm{m}$ ).

\subsection{Contact temperature of BFRC}

The contact temperature of BFRC increases with the increase in wear rate and co-efficient of friction in consistently as shown in Fig. 5.

The wear loss and the co-efficient of friction drops with increase in the temperature may be due to thermal softening of polymer matrix. The relationship of contact temperature and coefficient of friction of brake material is determined by the self lubrication fillers that are used in the composite. When the brake antifriction materials are formed on the surface and the counter face, the process of this formation is controlled by temperature and the material composition.

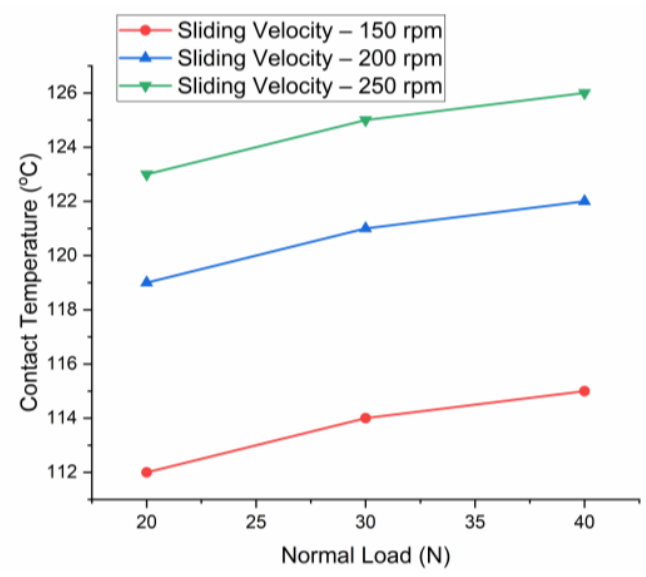

Fig. 5. BFRC temperature at contact surface.

\subsection{Tribological characteristics of AFRC}

Figure 6a represents the SEM image of AFRC, it can be observed that aramid fibres are randomly distributed in the matrix and there is a cluster formation may weak the bonding nature between the matrix and fibres. This may results in the reduction of hardness and compaction strength of the AFRC composites, which ultimately lead to more wear loss in this composites compared to other composites [34]. Voids could also be found in the composite which suggest that the sintering of the ingredients with the polymer matrix has not occurred properly, that leads to weak bonding $[34,35]$. Table 5 represents the wear test results obtained for AFRC. Figures $6 b$ and $6 c$ shows the coefficient of friction and wear loss appear to increase continuously at low to high sliding velocity with increase in load. This may be due to the reduction of the space between the two sliding surfaces causing more wear debris to be formed between the contact surfaces resulting in increased lubrication [18,20]. The frictional 
force between the contact surfaces are less compared to the applied force and hence the coefficient of friction increases and this may be due to the surface treatment of aramid fibers. The increase in load may results in debris formation which gets adhered to the sliding surfaces and piles up to form a much thick layer with a more contact area that serves as lubricant at the sliding interface there by reducing the coefficient of friction [41,42]. This concept may be correlated to the thermal and mechanical property of fiber which protects the polymer matrix from the severe wear at elevated temperature [43-45].

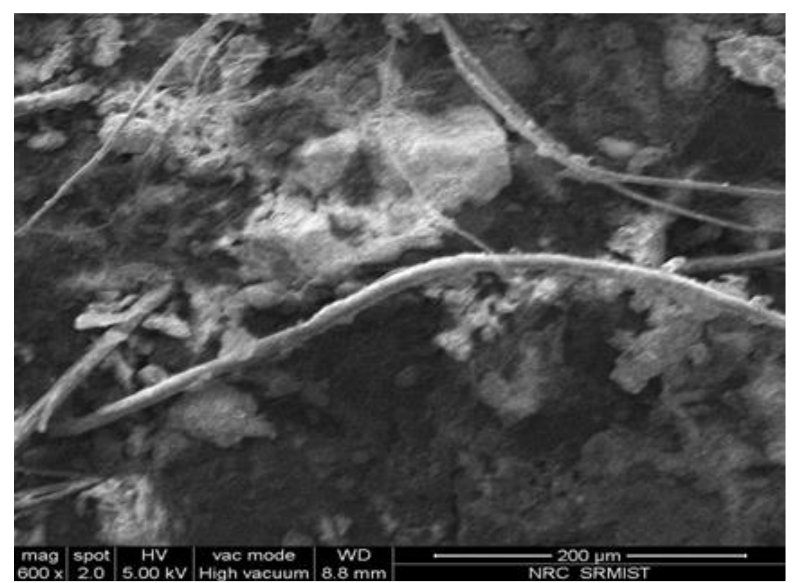

(a)

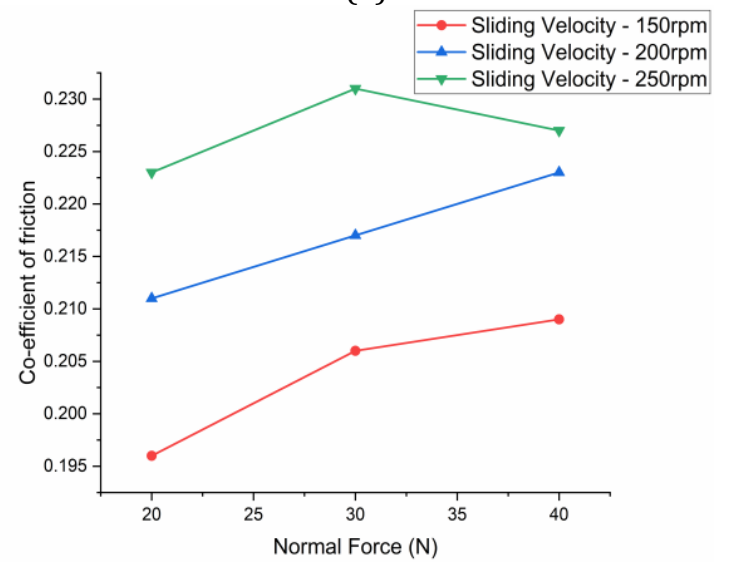

(b)

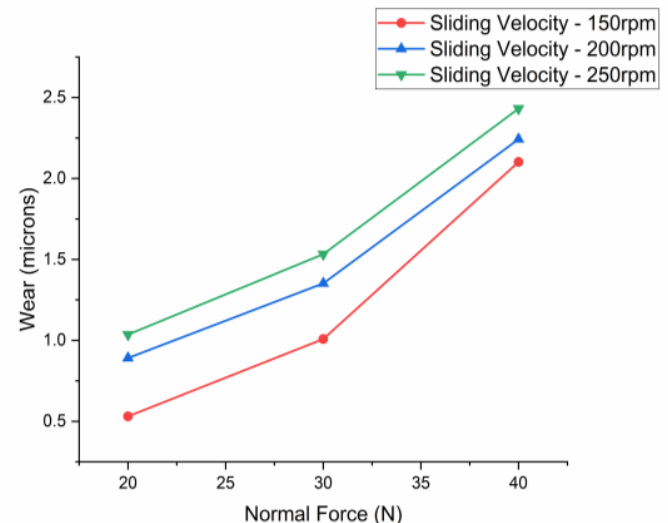

(c)

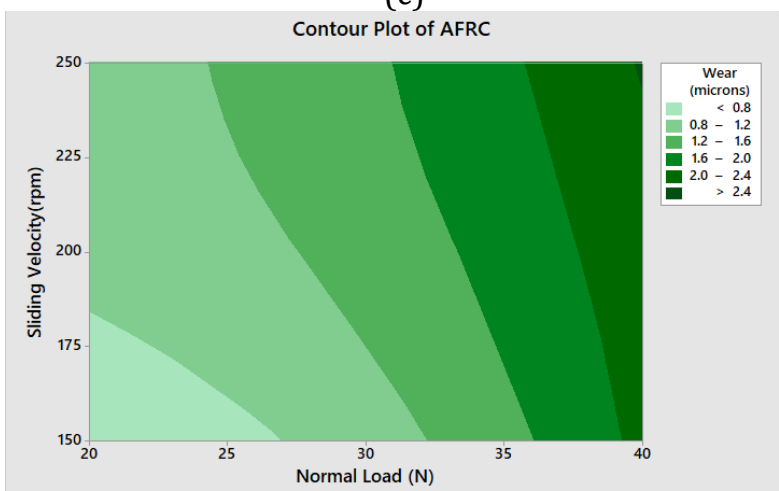

(d)

Fig. 6. (a) SEM Image of AFRC, (b) Coeff. of friction of AFRC, (c) wear loss of AFRC and (d) Contour plot of AFRC.

At higher sliding velocities the coefficient of friction has no major variation, at the same time wear loss reduces with raise in load, this might be because of the increase in temperature resulting in adhesion of fiber with the sliding surface making the further material removal difficult there by reducing wear loss to a greater extent [23]. Figure $6 \mathrm{~d}$ represents the contour plot of wear loss under normal load and sliding velocity of AFRC specimen. It can be inferred that around $40 \%$ of the contour area represents mild wear (wear loss between 0.5 to $1.5 \mu \mathrm{m}$ ), approximately $50 \%$ area represents sever wear region (wear loss between 1.5 to $2.1 \mu \mathrm{m}$ ) and finally approximately $20 \%$ represents area represents ultra-sever wear region (wear loss $>2.1 \mu \mathrm{m}$ ).

Table 5. Wear Loss and COF of AFRC specimens.

\begin{tabular}{|c|c|c|c|c|}
\hline Normal Load (N) & Sliding Velocity (rpm) & Wear Loss (microns) & Frictional coefficient $(\boldsymbol{\mu})$ & Contact Temperature ( $\left.{ }^{\circ} \mathbf{C}\right)$ \\
\hline 20 & 150 & 0.5307 & 0.196 & 116 \\
\hline 30 & 150 & 1.0084 & 0.206 & 116 \\
\hline 40 & 150 & 2.1019 & 0.209 & 118 \\
\hline 20 & 200 & 0.8908 & 0.211 & 120 \\
\hline 30 & 200 & 1.3524 & 0.217 & 124 \\
\hline 40 & 200 & 2.2431 & 0.223 & 127 \\
\hline 20 & 250 & 1.0361 & 0.223 & 128 \\
\hline 30 & 250 & 1.5324 & 0.231 & 130 \\
\hline 40 & 250 & 2.4320 & 0.227 & \\
\hline
\end{tabular}


Table 6. Wear Loss and COF of HFRC specimens.

\begin{tabular}{|c|c|c|c|c|}
\hline Normal Load (N) & Sliding Velocity (rpm) & Wear Loss (microns) & Frictional Coefficient $(\boldsymbol{\mu})$ & Contact Temperature $\left.\mathbf{~}^{\mathbf{0}} \mathbf{C}\right)$ \\
\hline 20 & 150 & 0.9554 & 0.196 & 97 \\
\hline 30 & 150 & 0.9908 & 0,209 & 101 \\
\hline 40 & 150 & 0.7851 & 0.203 & 103 \\
\hline 20 & 200 & 1.0328 & 0.211 & 107 \\
\hline 30 & 200 & 1.4862 & 0.226 & 106 \\
\hline 40 & 200 & 0.8067 & 0.223 & 110 \\
\hline 20 & 250 & 1.2031 & 0.232 & 109 \\
\hline 30 & 250 & 1.7341 & 0.246 & 113 \\
\hline 40 & 250 & 0.9325 & 0.249 & \\
\hline
\end{tabular}

\subsection{Contact temperature of AFRC}

When AFRC is subjected to wear test the contact temperature increases with the increase in the wear loss and the frictional coefficient is shown in Fig. 7. This may be due to the intermolecular dispersion forces.

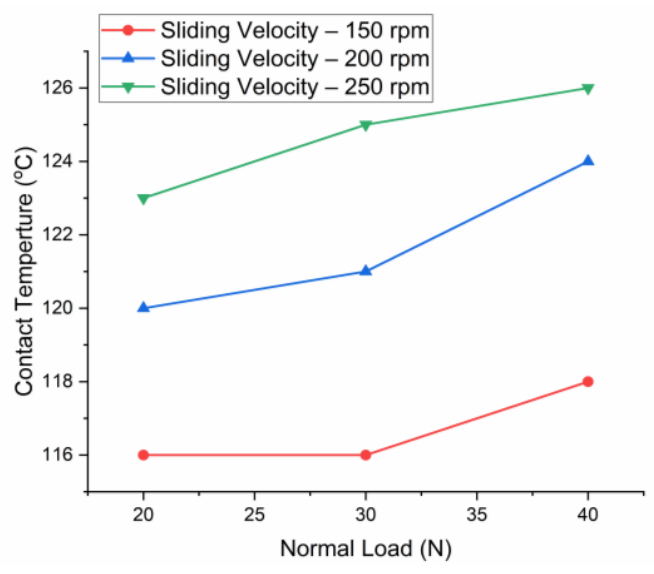

Fig. 7. AFRC temperature at contact surface.

The increase in temperature with the variation in the wear loss and coefficient of friction may also be due to the chemical composition and the nature of intermolecular interaction of polyimide binder. However the effect of temperature of the frictional properties of polyimide is characterized by a weak relationship between friction coefficient and temperature.

\subsection{Tribological characteristics of HFRC}

Figure 8a represents the structural image of HFRC that shows the aramid fiber got well entangled with the basalt fiber strands which increased the strength as well as density of the composite as a whole, better amalgamation of the fibers and other ingredients with the PI matrix could also be witnessed from the image. It is also noticed that sintering of the matrix taken place uniformly and the fibers have gone rooted deeply into the matrix and has fused well with rest of the ingredients, no voids could be seen as such, which ultimately leads to better wear performance of the composite as it is evident from the Figs. 8b and $8 \mathrm{c}$ representing the friction coefficient and wear loss based on normal load [46]. At all the loads and sliding velocities, the coefficient of friction seems to increase initially and then decreases gradually which can be attributed to a steady state period wherein the coefficient of friction becomes stable after the generation and peel off of the transfer film during the initial stage at which coefficient of friction is found to be much higher [47].

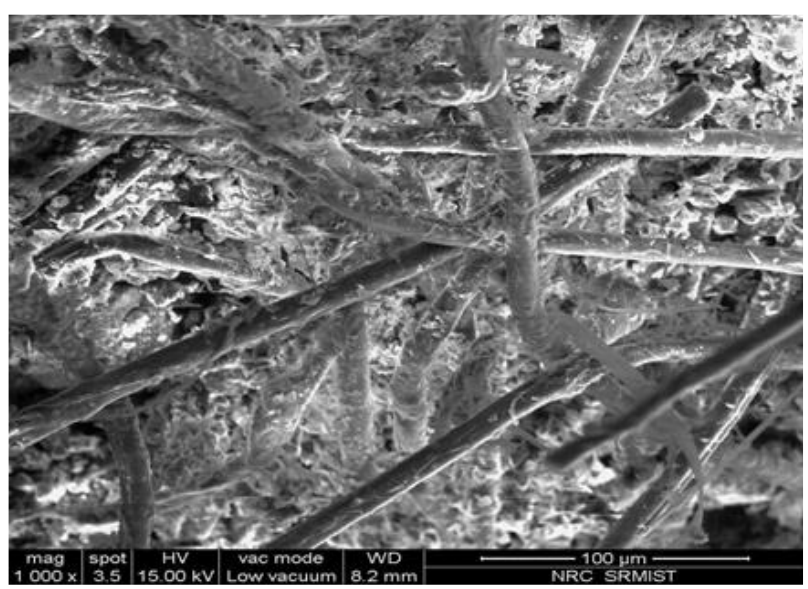

(a)

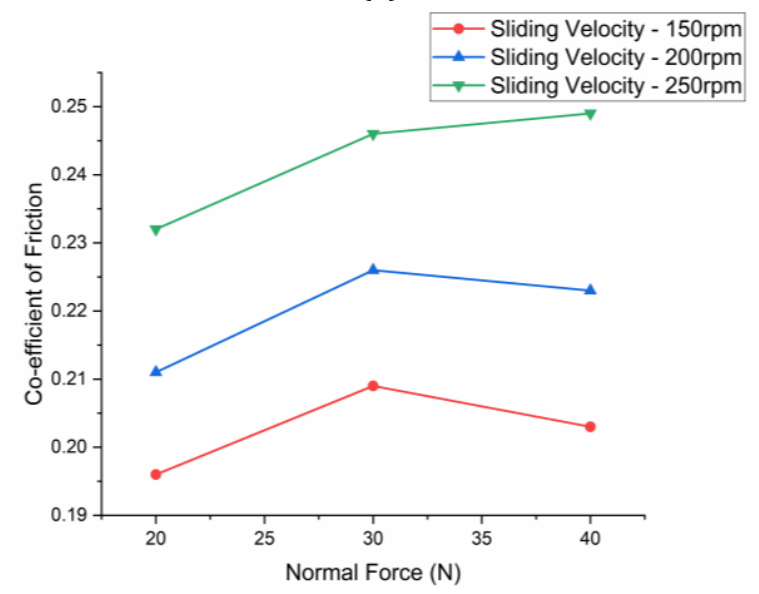

(b) 


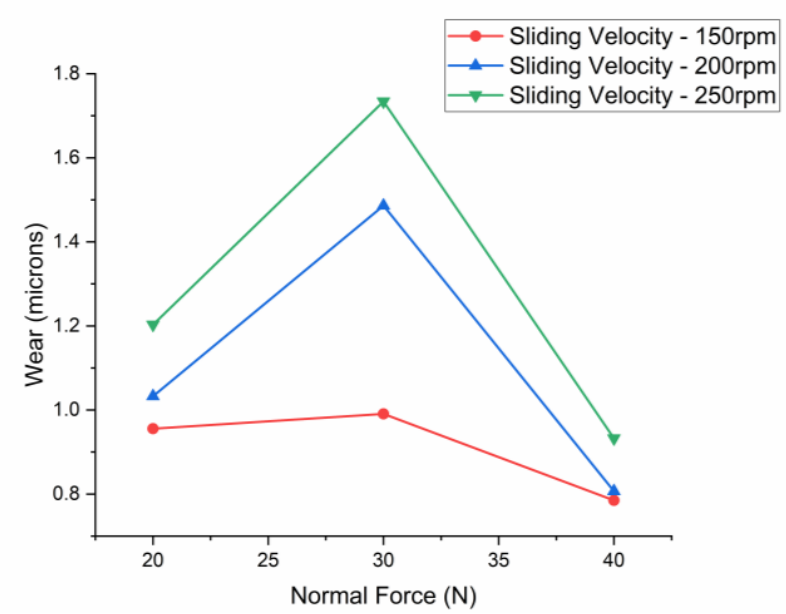

(c)

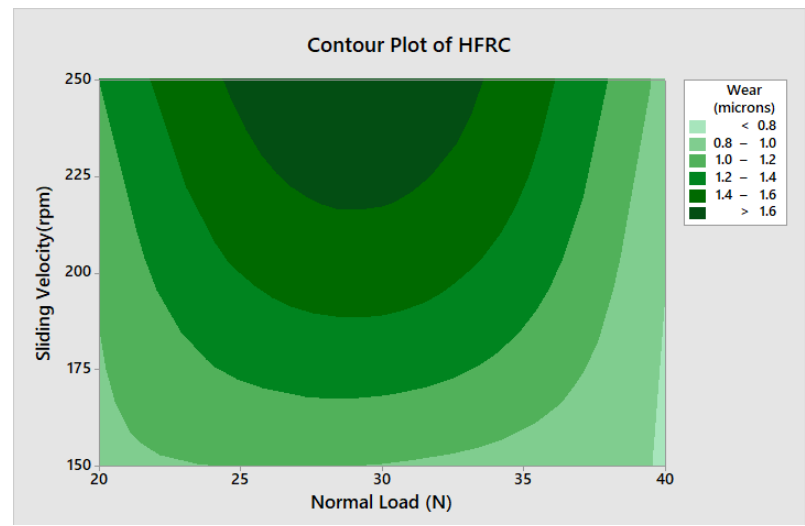

(d)

Fig. 8. (a) SEM Image of HFRC, (b) Coefficient of friction of HFRC, (c) wear rate of HFRC and (d) Contour plot of HFRC.

Table 6 represents the wear test results obtained for HFRC. Where as in case of wear loss at lower speeds the wear loss seems to be medium initially then increases because of initial rubbing of the two sliding surfaces which results in the formation of debris in between the friction surface that relatively increases the wear loss. When the temperature increases with further increase in load, this dense layer gets vanished and adapted to strong abrasives. Due to this the wear loss increases again [39].

The drop in wear loss occurs as the load increases, this may be because of the ironing mechanism caused by friction-induced heat which makes material removal from the pin more difficult [23]. At medium and higher speeds with increasing load, it is found that there is significant drop in wear and is found to be minimal which can be attributed to the mechanical and thermal behavior of the hybrid fiber reinforced composite as well as the exposure of well entangled basalt and aramid fibers at the sliding interfaces $[18,43,45,48]$. Figure $8 \mathrm{~d}$ represents the contour plot of the wear loss based on normal load and corresponding sliding velocity of HFRC specimen. It can be inferred that approximately $76 \%$ of the contour area represents mild wear (wear loss between 0.7 to $1.2 \mu \mathrm{m}$ ), around $6 \%$ area represents sever wear region (wear loss between 1 to $1.6 \mu \mathrm{m}$ ) and finally around $2 \%$ represents area represents ultra-sever wear region (wear loss is more than $1.6 \mu \mathrm{m}$ ).

\subsection{Contact temperature of HFRC}

The contact temperature varies with respect the wear loss and the frictional co-efficient are unpredictable. It was observed that the hybridization of fiber namely aramid and basalt fibres, which induce synergetic property that enhance the thermal stability of HRFC.

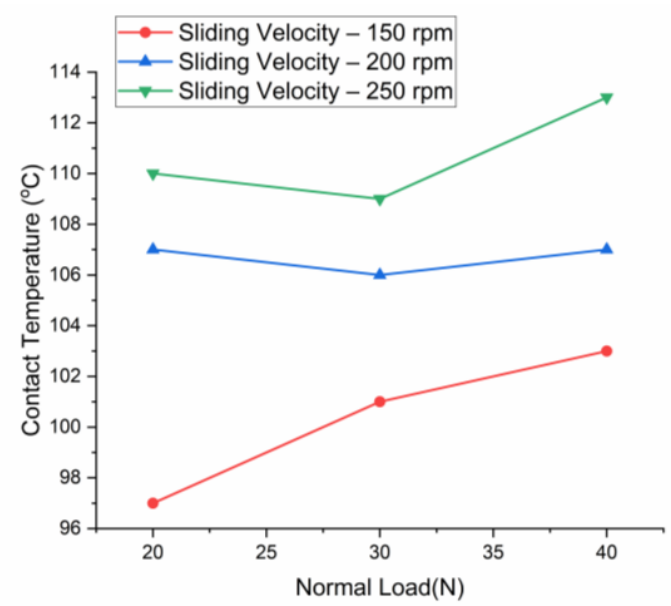

Fig. 9. HFRC temperature at contact surface.

This may be due to the inherent in compatibility that happened between the organic aramid fibre and inorganic basalt fibre. The actual area of contact and the shear strength of polymers in respective temperature ranges also affect the wear loss and coefficient of friction.

\subsection{DSC analysis of BFRC, AFRC and HFRC}

Figure 10 shows the DSC results of BFRC, AFRC and HFRC frictional composites and the output of the DSC test results obtained for each brake pad specimen is given in Table 7. The curve shows a heat flow as an exothermic process in all sliding condition and applied load. The glass transition temperature of BFRC, AFRC and HFRC are $236.3{ }^{\circ} \mathrm{C}, 242.36^{\circ} \mathrm{C}$ and $246.7^{\circ} \mathrm{C}$ respectively. AFRC exhibits low $\mathrm{T}_{\mathrm{g}}$ value may be due to the 
less $\mathrm{T}_{\mathrm{g}}$ value of aramid compared to basalt fibre. Whereas the glass transition temperature of basalt is high and hence the composites BFRC and HFRC have relatively better $\mathrm{T}_{\mathrm{g}}$ values.

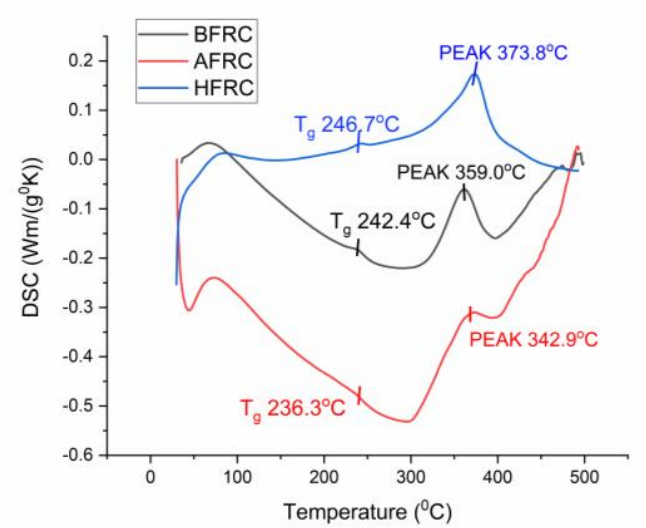

Fig. 10. DSC curve of the composites.

Table 7. Differential Scanning Calorimetry Results.

\begin{tabular}{|c|c|c|c|c|c|}
\hline \multirow{2}{*}{$\begin{array}{c}\text { Sl. } \\
\text { No }\end{array}$} & \multirow{2}{*}{ Specimen } & \multicolumn{2}{|c|}{$\begin{array}{c}\text { Glass Transition } \\
\text { Temperature }\end{array}$} & \multicolumn{2}{c|}{$\begin{array}{c}\text { Degradation } \\
\text { Temperature }\end{array}$} \\
\cline { 3 - 6 } & & $\begin{array}{c}\text { Mid } \\
\mathbf{(} \mathbf{C})\end{array}$ & $\begin{array}{c}\mathbf{C}_{\mathbf{p}} \\
(\mathbf{J} / \mathbf{g} \text { * K) }\end{array}$ & $\begin{array}{c}\text { Area } \\
\mathbf{( J / g )}\end{array}$ & $\begin{array}{c}\text { Peak } \\
\left({ }^{\circ} \mathbf{C}\right)\end{array}$ \\
\hline 1 & AFRC & 236.3 & 0.043 & 39.95 & 342.9 \\
\hline 2 & BFRC & 242.4 & 0.045 & 28.46 & 359.0 \\
\hline 3 & HFRC & 246.7 & 0.052 & 57.26 & 373.8 \\
\hline
\end{tabular}

An exothermic curve creeps after attaining the glass transition temperature by all the samples. In general after reaching a temperature of $300{ }^{\circ} \mathrm{C}$ temperature the is an endothermic fall in the DSC curve may be due to degradation of filler and binders. The degradation peaks are observed for BFRC, AFRC and HFRC composites are 342.9, 359 and $373.8{ }^{\circ} \mathrm{C}$ respectively. Predominantly above $300{ }^{\circ} \mathrm{C}$, the mass loss condensation stage is involved in formation of Polyimide ring amine group that results in mass loss [49]. From DSC curve we observe HFRC has the highest degradation temperature compared to AFRC and BFRC. Hence HFRC can be rated as best thermal stable material for frictional applications. It is also noted that due to the presents of basalt and aramid in HFRC, good bonding that is shown in the SEM image proves that the heat transfer along the fibres, improves the thermal stability of the composite rather that other composites [50,51].

\subsection{TGA analysis of BFRC, AFRC and HFRC}

The Figure 11 indicates TGA of HFRC, AFRC and HRFC composites. The TGA measures the mass loss with respect to the increase in temperature.
The Table 8 shows the degradation temperature of the composites. The TGA results provide information on thermal stability, changes in materials composition, kinetic parameters for chemical reactions in the sample, oxidative stability of the material and estimated life time. The weight loss mechanism may be due to materials decomposition, evaporation, reduction and desorption.

Table 8. Thermo GravimetryAnalysis Results.

\begin{tabular}{|c|c|c|c|}
\hline \multirow{2}{*}{ Sl. No. } & \multirow{2}{*}{$\begin{array}{c}\text { Specimen } \\
\text { Sample }\end{array}$} & \multicolumn{2}{|c|}{ Onset 2 } \\
\cline { 3 - 4 } & AFRC & $\mathbf{X ~ ( { } ^ { \circ } \mathbf { C } )}$ & $\mathbf{X ~ ( { } ^ { \circ } \mathbf { C } )}$ \\
\hline 1 & 345.14 & 694.91 \\
\hline 2 & BFRC & 355.93 & 743.92 \\
\hline 3 & HFRC & 361.06 & 812.23 \\
\hline
\end{tabular}

The weight gain in the TGA curve is due to the oxidation and absorption, all these reactions are kinetic processes depends on the state of reaction. The TGA curve exhibits a two stage degradation process, such as characterization and weight loss phases. The polymeric material remains virtually intact in the first phase $[49,52]$. The first decomposition temperature for AFRC occurs at $345.14{ }^{\circ} \mathrm{C}, 355.93{ }^{\circ} \mathrm{C}$ for BFRC and $361.06{ }^{\circ} \mathrm{C}$ for HFRC.

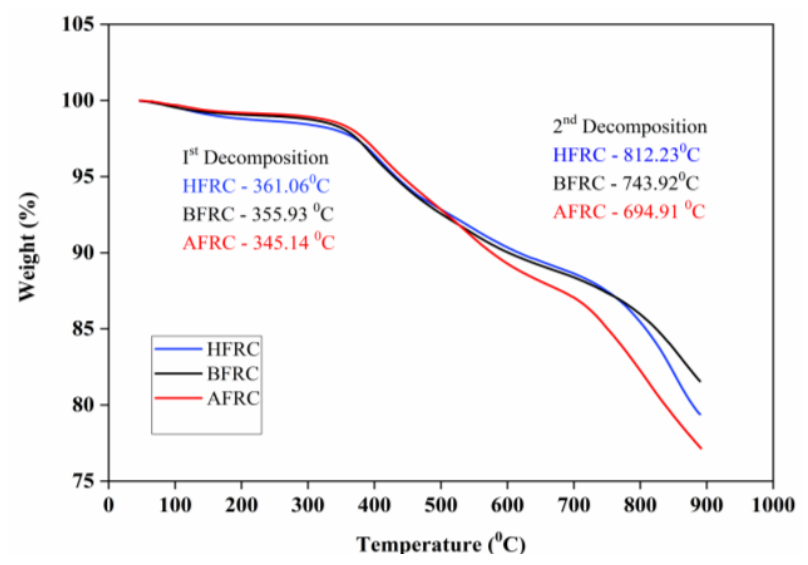

Fig. 11. TGA curve of the composites.

The second phase of decomposition of the matrix materials releases $\mathrm{H}_{2} \mathrm{O}, \mathrm{CO}_{2}, \mathrm{NH}_{3}$, etc. The mass at the stage just happens to lose due to the initial stage of polymerisation. HFRC decomposes at higher temperature due to the better heat with standing capacity. It is noted that when basalt contact hold more heat than the aramid fibre but when the aramid the heat transfer rate increases and hence the hybrid fibre composites ate more thermal stable than the individual [53]. The second phase of decomposition occurs after $600{ }^{\circ} \mathrm{C}$ temperature. 
HFRC hold good till $812.27{ }^{\circ} \mathrm{C}$ temperature rise, whereas the decomposition of AFRC and BFRC are $743.92{ }^{\circ} \mathrm{C}$ and $694.91{ }^{\circ} \mathrm{C}$ respectively. Overall it is observed that HFRC exhibits better thermal stability when compared to AFRC and BFRC composites [54,55].

\section{CONCLUSION}

Three different brake pad composites with basalt, aramid and there hybrid fibers were reinforced in polyimide binder were prepared, keeping all other ingredients constant and named as BFRC, AFRC and HFRC respectively. The prepared composites were tested for wear in pin-on-disc apparatus using EN31 steel, diameter of $100 \mathrm{~mm}$, and thickness of $60 \mathrm{~mm}$ as rotating disc.

- HFRC is found to be a better choices as an alternative for brake pad, since it showed higher wear resistance compared to other two composite used in this study.

- HFRC composite despite having a medium hardness of $42 \mathrm{HRB}$ proved to be effective in respect of wear rate in comparison to BFRC (50 HRB) and AFRC (35.5 HRB).

- From the obtained SEM images of the three different specimens, HFRC was found to have higher fusion of the fibers with PI and other ingredients matrix as compared to BFRC and AFRC.

- The mild wear regime was higher in HFRC as compared to BFRC and AFRC. This was obtained using MINITAB software.

- The temperature at the contact surface is less for HFRC compared to BFRC and AFRC. This indicates less frictional heat and less wear in HRFC [56].

- The DSc result showsmaximum glass transition temperature for HFRC. This is due to good bonding between the matrix nd the fibers [57].

- TGA analysis reveals that HFRC sample shows single degradation pattern as other composites. HFRC has better thermal stability, since it degardes at high temperature.

\section{REFERENCES}

[1] K.H. Sing, A. Kumar, R. Kumar, Optimization of quality and performance of brake pads using Taguchi's approach, International Journal of Scientific \& Engineering Research, vol. 5, iss. 7, pp. 632-639, 2014.

[2] B. Henderson, J.H. Haynes, Disc Brakes. The Haynes Automotive Brake Manual, In Haynes, North America, pp. 1-20, 1994.

[3] G. Xian, Z. Zhang, Sliding wear of polyetherimide matrix composites: I. Influence of short carbon fibre reinforcement, Wear, vol. 258, iss. 5-6, pp. 776-782, 2005, doi: 10.1016/j.wear.2004.09.054

[4] M. Palabiyik, S. Bahadur, Tribological studies of polyamide 6 and high-density polyethylene blends filled with PTFE and copper oxide and reinforced with short glass fibers, Wear, vol. 253, iss. 3-4, pp. 369-376, 2002, doi: 10.1016/S0043-1648(02)00144-8

[5] M.A. Balaji, K. Kalaichelvan, Thermal and fade aspects of a non-asbestos semi metallic disc brake pad formulation with two different resins, Advanced Materials Research, vol. 622-623, pp. 1559-1563, 2013 doi: 10.4028/www.scientific.net/AMR.622-623.1559

[6] J. Bijwe, Composites as friction materials: Recent developments in non-asbestos fiber reinforced friction materials-a review, Polymer composites, vol. 18, iss. 3, pp. 378-396, 1997, doi: $10.1002 /$ pc. 10289

[7] P.V. Gurunath, J. Bijwe, Friction and wear studies on brake-pad materials based on newly developed resin, Wear, vol. 263, iss. 7-12, pp. 1212-1219, 2007, doi: 10.1016/j.wear.2006.12.050

[8] H. Zula, N.D. Ghetiya, D. Pandya, Development of Friction Pad and Study of its Wear Characteristics, International journal for scientific research and development, vol. 4, iss. 11, pp. 316-319, 2017.

[9] X. Zhang, X. Pei, Q. Wang, Friction and wear properties of basalt fiber reinforced/solid lubricants filled polyimide composites under different sliding conditions, Journal of applied polymer science, vol. 114, iss. 3, pp. 17461752, 2009, doi: 10.1002/app.30517

[10] Q. Wang, X. Zhang, X. Pei, Study on the synergistic effect of carbon fiber and graphite and nanoparticle on the friction and wear behavior of polyimide composites, Materials \& Design, vol. 31, iss. 8, pp. 3761-3768, 2010, doi: 10.1016/j.matdes.2010.03.017 
[11] M. Lv, F. Zheng, Q. Wang, T. Wang, Y. Liang, Friction and wear behaviors of carbon and aramid fibers reinforced polyimide composites in simulated space environment, Tribology International, vol. 92, pp. 246-254, 2015, doi: 10.1016/j.triboint.2015.06.004

[12] S. Mahanta, S. Samanta, M. Chandrasekaran, Processing and investigation of tribological properties of basalt epoxy composites, Materials Today: Proceedings, vol. 4, iss. 8, pp. 81858191, 2017, doi: 10.1016/j.matpr.2017.07.160

[13] A Special Highlight on Basalt and Aramid Fiber Reinforced Plastic, available at: https://www.craftechind.com/a-specialhighlight-on-basalt-and-aramid-fiber-reinforcedplastic/, accessed: 25.11.2020.

[14] Y. Wang, X. Wang, D. Wu, Mechanical and tribological enhancement of polyoxymethylenebased composites with long basalt fiber through melt pultrusion, Composite Interfaces, vol. 23, no. iss. 8, pp. 743-761, 2016, doi: $10.1080 / 09276440.2016 .1168124$

[15] A.K. Bandaru, S. Patel, Y. Sachan, S. Ahmad, R. Alagirusamy, N. Bhatnagar, Mechanical behavior of Kevlar/basalt reinforced polypropylene composites, Composites Part A: Applied Science and Manufacturing, vol. 90, pp. 642-652, 2016, doi: 10.1016/j.compositesa.2016.08.031

[16] O.Y. Bozkurt, A. Erklig, M. Bulut, Hybridization effects on charpy impact behavior of basalt/aramid fiber reinforced hybrid composite laminates, Polymer Composites, vol. 39, iss. 2, pp. 467-475, 2018, doi: 10.1002/pc.23957

[17] V.V. Prasad, S. Talupula, A review on reinforcement of basalt and aramid (Kevlar 129) fibers, Materials Today: Proceedings, vol. 5, no. iss. 2, pp. 5993-5998, 2018, doi: 10.1016/j.matpr.2017.12.202

[18] S. Manoharan, R. Vijay, D.L. Singaravelu, S. Krishnaraj, B. Suresha, Tribological characterization of recycled basalt-aramid fiber reinforced hybrid friction composites using grey-based Taguchi approach, Materials Research Express, vol. 6, no. 6, p. 065301, 2019, doi: 10.1088/2053-1591/ab07ce

[19] O. Hasan, U. Ilyas, A. Gulsah, A Sitki. Determination of friction and wear behavior of organic dusts reinforced with the brake pads by using taguchi method, Proceedings on Engineering Sciences, vol. 1, no. 1, pp. 293-297, doi: 10.24874/PES01.01.037

[20] Y. Harun, P. Gencaga, H.A Huseyin, Effect of cashew nut shell liquid (cnsl) on tribological behavior of brake pad composite, Proceedings on Engineering Sciences, vol. 1, no. 1, pp. 341346, doi: 10.24874/PES01.01.044

[21] M. Kchaou, A. Sellami, R. Elleuch, H. Singh, Friction characteristics of a brake friction material under different braking conditions, Materials \& Design, vol. 52, pp. 533-540, 2013, doi: 10.1016/j.matdes.2013.05.015

[22] M. Eriksson, F. Bergman, S. Jacobson, On the nature of tribological contact in automotive brakes, Wear, vol. 252, iss. 1-2, pp. 26-36, 2002, doi: 10.1016/S0043-1648(01)00849-3

[23] A.K. Ilanko, S. Vijayaraghavan, Wear mechanism of flax/basalt fiber-reinforced eco-friendly brake friction materials, Tribology-Materials, Surfaces \& Interfaces, vol. 11, iss. 1, pp. 47-52, 2017, doi: 10.1080/17515831.2017.1299323

[24] S. Bahadur, Q. Fu, D. Gong, The effect of reinforcement and the synergism between CuS and carbon fiber on the wear of nylon, Wear, vol. 178, iss. 1-2, pp. 123-130, 1994, doi: 10.1016/0043-1648(94)90137-6

[25] S. Naficy, H. Garmabi, Study of the effective parameters on mechanical and electrical properties of carbon black filled PP/PA6 microfibrillar composites, Composites science and technology, vol. 67, iss. 15-16, pp. 3233-3241, 2007, doi: 10.1016/j.compscitech.2007.04.001

[26] S.P. Bao, S.C. Tjong, Impact essential work of fracture of polypropylene/montmorillonite nanocomposites toughened with SEBS-g-MA elastomer, Composites Part A: Applied Science and Manufacturing, vol. 38, iss. 2, pp. 378-387, 2007, doi: 10.1016/j.compositesa.2006.03.005

[27] I. Gonzalez, J.I. Eguiazabal, J. Nazabal, Nanocomposites based on a polyamide 6/maleated styrene-butylene-co-ethylene-styrene blend: Effects of clay loading on morphology and mechanical properties, European Polymer Journal, vol. 42, iss. 11, pp. 2905-2913, 2006, doi: 10.1016/j.eurpolymj.2006.07.014

[28] X.G. Tang, W. Yang, G.F. Shan, M.B. Yang, B.H. $\mathrm{Xie}, \mathrm{Q}$. Fu, Double yielding in PA6/TPV-MAH blends: Effect of dispersed phase with different content, modulus, Polymer, vol. 48, iss. 25, pp. 7404-7413, 2007, doi: 10.1016/j.polymer.2007.09.052

[29] B. Ou, D. Li, Y. Liu, Compatibilizing effect of maleated polypropylene on the mechanical properties of injection molded polypropylene/polyamide6/functionalized TiO2 nanocomposites, Composites science and technology, vol. 69, iss. 3-4, pp. 421-426, 2009 , doi: 10.1016/j.compscitech.2008.11.010 
[30] S. Mohanty, Y. P. Chugh, Development of fly ashbased automotive brake lining, Tribology International, vol. 40, iss. 7, pp. 1217-1224, 2007, doi: 10.1016/j.triboint.2007.01.005

[31] G. Cueva, A. Sinatora, W.L. Guesser, A.P. Tschiptschin, Wear resistance of cast irons used in brake disc rotors. Wear, vol. 255, iss. 7-12, pp. 1256-1260, 2003, doi: 10.1016/S00431648(03)00146-7

[32] R. Holinksi, D. Hesse, Changes at interfaces of friction components during braking, Journal of Automobile Engineering, vol. 217, iss. 9, pp. 765770, 2003, doi: 10.1177/095440700321700901

[33] K. Pareek, P. Saha, Basalt Fiber and Its Composites: An Overview, in National Conference on Advances in Structural Technologies, 1-3 Febrary, 2019, CoAST-2019, Department of Civil Engineering, National Institute of Technology Silchar, pp. 53-62.

[34] M. Fahim, N. Chand, Tribology of natural fiber polymer composites, Elsevier, 2008.

[35] B. Wei, H. Cao, S. Song, Surface modification and characterization of basalt fibers with hybrid sizings, Composites Part A: Applied Science and Manufacturing, vol. 42, iss. 1, pp. 22-29, 2011., doi: 10.1016/j.compositesa.2010.09.010

[36] I. Mutlu, I. Sugözü, A. Keskin, The effects of porosity in friction performance of brake pad using waste tire dust, Polímeros, vol. 25, no. 5, pp. 440-446, 2015, doi: 10.1590/0104-1428.1860

[37] J. Bao, Z. Zhu, M. Tong, Y. Yin, Y. Peng, Influence of braking pressure on tribological performance of non-asbestos brake shoe for mine hoister during emergency braking, Industrial lubrication and tribology, vol. 64, iss. 4, 2012, doi: 10.1108/00368791211232780

[38] X. Xiao, Y. Yin, J. Bao, L. Lu, X. Feng, Review on the friction and wear of brake materials, Advances in Mechanical Engineering, vol. 8, iss. 5, pp. 1687814016647300, 2016, doi: $10.1177 / 1687814016647300$

[39] B. Öztürk, F. Arslan, S.U. Öztürk, Hot wear properties of ceramic and basalt fiber reinforced hybrid friction materials, Tribology International, vol. 40, iss. 1, pp. 37-48, 2007, doi: 10.1016/j.triboint.2006.01.027

[40] G. Zhao, I. Hussainova, M. Antonov, Q. Wang, T. Wang, D.L. Yung, Effect of temperature on sliding and erosive wear of fiber reinforced polyimide hybrids, Tribology International, vol. 82, pp. 525-533, 2015, doi: 10.1016/j.triboint.2014.01.019

[41] L. Wang, Y. Li, X.H. Guo, Study on friction and wear property of train powder metallurgy brake disc, Locomotive and Rolling Stock Technol, vol. 5, pp. 27-28, 2008.

[42] G.H. Jang, K.H. Cho, S.B. Park, W.G. Lee, U.S. Hong, H. Jang, Tribological properties of $\mathrm{C} / \mathrm{C}$-SiC composites for brake discs, Metals and materials international, vol. 16, pp. 61-66, 2010, doi: $10.1007 /$ s12540-010-0061-4

[43] Y. Yao, D. Zhu, H. Zhang, G. Li, B. Mobasher, Tensile behaviors of basalt, carbon, glass, and aramid fabrics under various strain rates, Journal of Materials in Civil Engineering, vol. 28, iss. 9, pp. 04016081, 2016, doi: 10.1061/(ASCE)MT.1943-5533.0001587

[44] M.S. Santhosh, R. Sasikumar, T. Thangavel, A. Pradeep, K. Poovarasan, S. Periyasamy, T. Premkumar, Fabrication and Characterization of Basalt/ Kevlar/ Aluminium Fiber Metal Laminates for Automobile Applications, International Journal of Materials Science, vol. 14, no. 1, pp. 1-9, 2019.

[45] J. Li, The effect of the addition of graphite on tribological properties of glass fibre-reinforced polyimide composites, Proceedings of the Institution of Mechanical Engineers, Part J: Journal of Engineering Tribology, vol. 224, iss. 3, pp. 279-284, 2010, doi: 10.1243/13506501JET638

[46] J. Li, X.H. Cheng, The effect of surface treatment of carbon fiber on the flexural property of thermoplastic polyimide composite, Composite Interfaces, vol. 15, iss. 5, pp. 515-526, 2008, doi: $10.1163 / 156855408784655319$

[47] G. Zhao, I. Hussainova, M. Antonov, Q. Wang, T. Wang, Friction and wear of fiber reinforced polyimide composites, Wear, vol. 312, iss. 1-2, pp. 122-129, 2013, doi: 10.1016/j.wear.2012.12.019

[48] H. Jamshaid, R. Mishra, A green material from rock: basalt fiber-a review, The Journal of The Textile Institute, vol. 107, iss. 7, pp. 923-937, 2016, doi: 10.1080/00405000.2015.1071940

[49] E. Papadopoulou, K. Chrissafis, Thermal study of phenol-Formaldehyde resin modified with cashew nut shell liquid, Thermochimica Acta, vol. 512, iss. 1-2, pp. 105-109, 2011, doi: 10.1016/j.tca.2010.09.008

[50] S. Rwawiire, B. Tomkova, Morphological, thermal, and mechanical characterization of Sansevieria trifasciata fibers, Journal of Natural Fibers, iss. 3, pp. 201-210, 2015, doi: $10.1080 / 15440478.2014 .914006$

[51] V. Titok, V. Leontiev, L. Shostak, L. Khotyleva, Thermogravimetric analysis of the flax bast fibre bundle, Journal of Natural Fibers, vol. 3, iss. 1, pp. 35-41, 2006, doi:10.1300/J395v03n01_04 
[52] A.P. Mouritz, A. G. Gibson, Fire properties of polymer composite materials, Springer, 2006.

[53] J. Liu, J. Yang, M. Chen, L. Lei, Z. Wu, Effect of Sio2, Al2o3 on heat resistance of basalt fiber, Thermochimica Acta, vol. 660, pp. 56-80, 2018. doi: 10.1016/j.tca.2017.12.023

[54] A. Knop, L. A. Pilato, Modified and thermalresistant resins, in Phenolic Resins, Berlin, Heidelberg: Springer, 1985.

[55] K. Pielichowski, J. Njuguna, Thermal degradation of polymeric materials, Shawbury, Surrey: RAPRA Technologies Limited, 2005.
[56] A.A.J. Kumar, V. Srinivasan, Wear Behavior of Chitosan-Filled Polylactic Acid/Basalt Fiber Hybrid Composites, Advances in Polymer Technology, vol.37, iss. 3, pp. 898-905, 2016, doi: 10.1002/adv.21735

[57] I.A. Kumar, A.A.J. Kumar, M. prakash, Thermal Characterization of Flax/ Basalt Fiber Reinforced Phenol Resin Brake Pad Material: Effective Replacement of Asbestos, Journal of Natural Fibers, pp. 1-11, 2019. doi: 10.1080/15440478.2019.1691114 